\title{
Experimental evaluation of allergenic properties of Bisphenol-5
}

\author{
R. M. Ahmadullin ${ }^{1}, R$. S. Muhammadiev ${ }^{2}$ and L. R. Valiullin ${ }^{2, *}$ \\ ${ }^{1}$ AhmadullinS Science and Technologies, Research and Development Center, 420139 Kazan, Russia \\ ${ }^{2}$ Federal Center of Toxicological, Radiation and Biological Safety - Russian Scientific Research Veterinary Institute, \\ 420075 Kazan, Russia
}

\begin{abstract}
The paper presents the results of preclinical studies of the allergenic properties of a new drug bisphenol-5, which has pronounced anti-radical activity. An experimental study of the antioxidant was carried out in doses of $2,5,20 \mathrm{mg} / \mathrm{kg}$ in guinea pigs and rabbits. It was shown that bisphenol-5 is not able to cause a general anaphylaxis reaction (anaphylactic shock). By the method of skin applications, the absence of allergenic effects of the drug in animals was found. During the formulation of conjunctival tests in experimental and control animals, signs of hypersensitivity, both immediate and delayed, were not observed with respect to the test drug. Changes in body temperature, pulse rate, and the number of respiratory movements as a result of clinical studies of the state of the animal organism after applying bisphenol-5 were also not recorded. Thus, the drug Besphenol-5 in the studied doses and under the selected experimental conditions does not have a negative effect on the body of laboratory animals and does not have allergenic properties.
\end{abstract}

\section{Introduction}

The need to intensify the production of livestock products is associated with a regular population growth and an increasing need for good nutrition of people [1]. Balancing diets with regards to amino acids and various nutrients is one of the key conditions for maintaining the optimal nature of metabolic processes and regulating the physiological functions of the body [2,3]. Thus, the increase in animal productivity greatly depends on good nutrition, which affects the quality and nutrition of the main products of livestock farming $[4,5]$.

In modern conditions of agro-industrial complexes, the lack of feed and their low quality, unbalanced diets, poor living conditions of animals lead to a decrease in their adaptive capacities, which causes diseases associated with metabolic disorders develop $[3,6]$. Antioxidants being a specific group of compounds of various nature, whose mechanism of action is associated with a slowdown of redox processes in a macroorganism by binding free radicals (reactive oxygen species) are used to eliminate the above consequences in the animals growth technology [7]. A number of researchers indicate that animal meat obtained after intensive fattening with synthetic antioxidants as well as its processed products have positive qualitative characteristics [7-9]. The use of antioxidant preparations also prevents oxidative processes in feeds [10], which, in turn, leads to the efficient use of feed nutrients and reduce their costs per unit of production.

Currently, a wide range of compounds of various origins that have pronounced antioxidant properties are used as feed additives in animal breeding $[5,10,11]$. In this regard, the new substance is 4.4'-bis (2,6-di-tretbutylphenol). It is a lipophilic organic substance that is a synthetic spatially substituted antioxidant of the phenol class [12]. Unlike its analogues 2,6-ditretbutyl and 4nonylphenol, it has a more pronounced antioxidant activity and high efficiency. Foreign researchers have shown that 4,4'-bis (2,6-di-tret-butylphenol) inhibits the type II cytosolic carbonic anhydrase involved in the process of carbon dioxide hydration [13]. 4,4'-bis (2,6di-tret-butylphenol) as well as 5-methylenedisalicylic acid is capable of inhibiting the expression of $\alpha$-toxin Staphylococcusaureus by blocking the DNA-binding activity of the protein regulator of MgrA transcription.

Preclinical studies of a new therapeutic agent are determined by the requirements for existing drugs obtained by the new technology, and are based, first of all, on the study of its biological properties and safety. The resulting preparation with antioxidant properties should be tested for all biological properties, including allergenic ones, in accordance with the regulatory documents [14].

The mechanism of an allergic reaction development is due to the physicochemical properties of a drug, its dose, method and duration of its administration, as well as the characteristics of the macroorganism to respond to environmental influences by changing their life. Hypersensitivity reactions can manifest themselves in two main types, specifically, an immediate type reaction, associated with humoral immune mechanisms and occurring quickly (15-25 min) after contact with an antigen, and a delayed type reaction, associated with cellular immune mechanisms and developing longer (for 24-48 hours) [15]. The study of new therapeutic agents

Corresponding author: valiullin27@mail.ru 
for allergenicity should contain a set of allergodiagnostic methods necessary in each particular case, which will reliably identify various types of hypersensitivity $[1,4]$.

The purpose of this study was to evaluate the allergenic properties of the new bisphenol-5 preparation in invivo experiments.

\section{Materials and Methods}

The study was conducted in accordance with the allEuropean requirements for animals used in experiments (Strasbourg, 1986). The experimental animals were in the same conditions of keeping and feeding [16]. Environmental parameters corresponded to the sanitary and hygienic standards established for bioclinics (vivariums).

We used a chemical compound synthesized in the laboratory for oxidants synthesis of Kazan National Research Technological University. KNRTU has developed the methods for producing 4,4'-bis (2,6-ditret-butylphenol). As well, 3,3',5,5'-tetra-tertbutyldiphenoquinone was developed from hydroquinone by its alkaline oxidative dehydrogenation [12]. A passport, containing various characteristics being formula, molecular weight, NMR spectra, etc. was submitted to the laboratory sample. The resulting preparation with patent purity was given the name bisphenol with the corresponding number. Bisphenol-5 is a white crystalline powder with a yellowish-olive tint and a weak characteristic odor, insoluble in water, highly soluble in DMSO (dimethyl sulfoxide) and alcohol.

Guinea pigs and rabbits were kept in individual cages with free access to food and water. On the front wall of the cage there was a feeder and an automatic drinking bowl. Sawdust was used as bedding. The bedding was digested beforehand. The animals were fed in accordance with zootechnical standards [17]. The feed was kept in a room (warehouse) especially designated for this purpose. The animals were kept under the controlled environmental conditions $\left(15-18^{\circ} \mathrm{C}\right.$ and $50-65 \%$ of relative humidity). Cages were cleaned daily. Clinically healthy animals kept on a standard diet and 21 day's sequestration prior to the experiment were selected.

Groups of animals were formed on the basis of analogues with regards to account age, live weight and gender. The maximum difference in mass did not exceed $10 \%$ among animals of one group.

The anaphylactogenic activity of the antioxidant preparation bisphenol-5 was evaluated by the reaction of general anaphylaxis (anaphylactic shock) [14]. 32 laboratory guinea pigs with an initial body weight of 350-400 g, obtained from the laboratory animals vivarium Federal State Budgetary Institution "FCTRBS-ARRVI" were used as experimental animals. The experimental and control groups contained 6 animals each.

Experimental animals were divided into 4 groups:

1. Group 1: animals were sensitized with a $2 \%$ alcohol solution (negative control).

2. Group 2: animals were sensitized with a $0.6 \%$ solution of chicken egg protein whose main allergenic component is ovalbumin (positive control).
3. Group 3: guinea pigs were sensitized with bisphenol-5, dissolved in $2 \%$ alcohol, at the dose equivalent to one therapeutic dose $(2 \mathrm{mg} / \mathrm{kg})$.

4. Group 4: animals were sensitized with bisphenol-5 in the dose equivalent to ten therapeutic doses (20 mg/kg).

The guinea pigs were administered with the test drug in an effective therapeutic dose and in the dose 10 times higher than that one: the first injection was subcutaneous, the next two doses were given intramuscularly every second day in the thigh area and a resolving injection was made intravenously on the $14^{\text {th }}-21^{\text {st }}$ day after sensitizing injection. The resolving dose was equal to the total sensitizing dose. Resolving injection on the $14^{\text {th }}-21^{\text {st }}$ day was introduced to the control group of animals that received only a solvent (negative control) or ovalbumin (positive control).

Anaphylactic shock intensity (in Weigle indices) was accounted according to the formula:

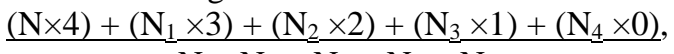

$\mathrm{N}+\mathrm{N}_{1}+\mathrm{N}_{2}+\mathrm{N}_{3}+\mathrm{N}_{4}$

where $\mathrm{N}$ is the number of guinea pigs that died;

$\mathrm{N}_{1}$ is the number of guinea pigs that developed severe shock;

$\mathrm{N}_{2}$ is the number of guinea pigs that developed moderate shock;

$\mathrm{N}_{3}$ is the number of guinea pigs that developed a mild shock;

$\mathrm{N}_{4}$ is the number of guinea pigs in which shock did not occur.

The intensity of anaphylactic shock in animals on the effect of the drug was evaluated in the Weigle index [18]

The experiments on the sensitizing (irritating) effect of an antioxidant prepared on the basis of liquid paraffin were carried out on 24 guinea pigs weighing 350-400 g and 24 rabbits weighing $1.8-2.0 \mathrm{~kg}$ using skin application method and conjunctival test. The number of animals in the experimental and control groups was equal to 6 .

In the first series of studies, 20 repeated skin applications of bisphenol-5 were administered in doses of $2,5,20 \mathrm{mg} / \mathrm{kg}$ on the sections of a body lateral surface, closer to the middle part of the body $\left(2\right.$ by $2 \mathrm{~cm}^{2}$ in size) of guinea pigs and ( 5 by $5 \mathrm{~cm}^{2}$ ) of rabbits 5 times a week. The test drug was applied in a uniform layer in the amount of 3 drops to the entire application area using an eyedropper. Guinea pigs or rabbits of the control group were covered with liquid paraffin. The animals were kept in individual cages and plastic collars preventing them from licking the drug were attached to their necks.

The skin response to the antioxidant effect was evaluated after 10, 20 applications in points on the scale of skin samples assessment [14]. The magnitude of edema was determined by measuring the skin fold thickness (in mm) using the thickness gauge TR-1-10.

In the second series of experiments, the sensitizing effect of bisphenol-5 was determined on the mucous membrane of the right eye of guinea pigs or rabbits, applying one drop of the sample under an upper eyelid on the anterior segment of the eye by means of an eyedropper with an elongated thin end. A control animal 
was applied with $2 \%$ alcohol. The reaction of the mucous membrane of the experimental eye, eyelid and cornea was recorded 15 minutes after the drug exposure (fast reaction) at doses of $2,5,20 \mathrm{mg} / \mathrm{kg}$ and after 24 , 48 hours of observation (delayed hypersensitivity).

The results were evaluated on the following scale (in points) [14]:

0 denoted no reaction;

1 slight redness of the lacrimal duct;

2 redness of the lacrimal duct and sclera in the direction of the cornea;

3 redness of the entire conjunctiva and sclera. The reaction is accompanied by itching and when combing the paws, purulent ophthalmitis may develop.

The sensitizing effect of the studied antioxidant was also evaluated by the following indicators: change in behavior and general condition of animals, their appetite, temperature and body weight; condition of the coat and skin, inflammation of the skin by measuring the skin fold thickness with callipers; the intensity of hair growth was measured by cutting tufts and measuring their length in millimeters [19].

Experimental data was statistically processed using the generally accepted method of variation statistics. For each sample, the arithmetic mean and their standard errors were calculated using the standard Microsoft OfficeExcel 2013 software package. When evaluating the differences between the groups, the Student's t-test was used. The differences were considered statistically significant at a $95 \%$ confidence level $(\mathrm{p} \leq 0.05)$.

\section{Results and Discussion}

The anaphylactogenic effect of the antioxidant preparation bisphenol-5 was studied in general anaphylaxis reactions in guinea pigs. After quarantine, the guinea pigs were divided into 4 groups according to the principle of analogues: experimental $(2,20 \mathrm{mg} / \mathrm{kg}$ ) and control groups, 8 animals in each. The experimental animals of the first set of experiments were sensitized by administrating the test compound at a dose of $2 \mu \mathrm{g} / \mathrm{kg}$ (therapeutic dose). The first injection was subcutaneous, the second and third ones were made intramuscularly and every other day. Experimental animals of the second set of experiments were sensitized by the drug administration at a dose of $20 \mathrm{mg} / \mathrm{kg}$ (10 times the amount of the therapeutic dose) according to the same scheme. Resolving injection of antioxidant was administered intravenously on the $21^{\text {st }}$ day from the moment sensitization was initiated. The animals of the control group were injected with a $2 \%$ alcohol solution (negative control) or $0.26 \%$ chicken egg protein solution (positive control) according to the same technique.

Assessment of anaphylactogenic activity showed that the test agent did not cause an anaphylactic reaction in guinea pigs of the experimental and control (negative control) groups. Signs of anxiety, rapid breathing, scratching of muzzles, involuntary urination, defecation, as well as the signs of breath shortness or paroxysms, pronounced symptoms of bronchospasm, noted in the case of anaphylaxis, were not observed.
The general condition of the animals was satisfactory, the mass of animals corresponded to the age-related physiological norms, and no changes in their behavior and appetite were detected. No significant differences were found in body temperature and live weight in the control and experimental groups of animals as well. The coat was not ruffled and no contact dermatitis has been detected. Guinea pigs did not lose their ability to stay on their paws, all animals remained alive.

The drug bisphenol-5 impact on the intensity of anaphylactic shock in guinea pigs is presented in table 1.

Table 1. Evaluation of the general anaphylaxis reaction in guinea pigs after administrating bisphenol-5

\begin{tabular}{|c|c|c|}
\hline Groups of animals & $\begin{array}{c}\text { Number of } \\
\text { animals }\end{array}$ & $\begin{array}{c}\text { Weigle } \\
\text { reaction index }\end{array}$ \\
\hline $\begin{array}{c}\text { Group 1 (negative } \\
\text { control) }\end{array}$ & 8 & 0 \\
\hline Group 2 (positive control) & 8 & $3.3 \pm 0,2$ \\
\hline Group 3 $(2 \mathrm{mg} / \mathrm{kg})$ & 8 & 0 \\
\hline Group 4 $(20 \mathrm{mg} / \mathrm{kg})$ & 8 & 0 \\
\hline
\end{tabular}

In groups 3 and 4 , injection of the test drug in doses of 2 and $20 \mathrm{mg} / \mathrm{kg}$, respectively, did not cause an anaphylactic reaction in any of the animals. Weigl indices for each animal were equal to 0 . The average Weigl index in groups 3 and 4 was equal to 0 . The absence of anaphylactogenic activity was also observed in group 1 (negative control), the average Weigl index was 0 .

In group 2 (positive control), all guinea pigs sensitized with a chicken egg protein solution developed an anaphylactic reaction. The average Weigl index in group 2 was $3.3 \pm 0.2$.

Thus, the results of a general anaphylaxis reaction (anaphylactic shock) testify to the absence of anaphylactogenic properties of bastophenol-5 both in the therapeutic dose and in a dose 10 times higher than that.

In the first set of experiments, the sensitizing (irritating) effect of the antioxidant specimen bisphenol5 was determined by the method of skin applications. After quarantine guinea pigs and rabbits were divided into 4 groups according to the principle of analogues. The groups were as follows: experimental (2, 5, $20 \mathrm{mg} / \mathrm{kg}$ ) and control 6 animals in each group. The skin-sensitizing effect of the drug was studied by its repeated application to the clipped back areas of experimental guinea pigs.

Two days before the start of the experiment, back sections were prepared, avoiding mechanical damage to the skin. On an epilated surface, the preparation was applied daily during 2 weeks in the amount of 2, 5, 20 mg per each kilogram of animal's body weight, evenly distributing it over the entire surface. The sensitizing effect of the sample was compared with a control group of guinea pigs or rabbits, which were similarly covered with paraffin oil.

It should be noted that, in the study of the sensitizing effect on the animals' skin, it was taken into account that functional disorders of the skin were characterized by the appearance of varying degrees of the severity of 
erythema, edema, cracks and ulcerations. In addition, to the establish severity of the inflammatory reaction, before and after application of the resolving dose of antioxidant, changes in skin temperature, animals' weight, the skin fold thickness and the skin condition at the site of application were noted. The degree of erythema and edema was summed up for each experimental animal, and afterwards the average score for the severity of the irritant effect for a group of experimental animals was calculated.

As a result of studying the sensitizing effect of bisphenol-5 with a single application on animals' skin, there were no signs of erythema, edema and other pathological changes noted, and the body temperature at the sites of compound applications did not change. There were no differences between the control and experimental groups of animals (Tables 2 and 3 ).

Based on the data obtained, it can be concluded that a single skin application of the test agent in the doses of 2 , $5,20 \mathrm{mg} / \mathrm{kg}$ to guinea pigs and rabbits does not damage their skin in the form of erythema or edema.

The results of the studies on the bisphenol-5 sensitizing effect with repeated use on the animals' skin were similar to the data obtained by studying the irritant effect of the drug with its single use (Fig. 1).

Table 2. Characteristics of bisphenol-5 sensitizing effect with a single multiple application on the skin of guinea pigs and rabbits

\begin{tabular}{|c|c|c|c|c|}
\hline Groups of animals & \multicolumn{2}{|c|}{$\begin{array}{c}\text { Numerical } \\
\text { score }\end{array}$} & \multicolumn{2}{c|}{ Irritant effect } \\
\cline { 2 - 5 } & $\begin{array}{c}\text { Guinea } \\
\text { pigs }\end{array}$ & Rabbits & $\begin{array}{c}\text { Guinea } \\
\text { pigs }\end{array}$ & Rabbits \\
\hline Group 1 (negative control) & 0 & 0 & missing & missing \\
\hline Group 2 $(2 \mathrm{mg} / \mathrm{kg})$ & 0 & 0 & missing & missing \\
\hline Group 3 $(5 \mathrm{mg} / \mathrm{kg})$ & 0 & 0 & missing & missing \\
\hline Group 4 (20 mg/kg) & 0 & 0 & missing & missing \\
\hline
\end{tabular}

Table 3. Effect of bisphenol-5 with a single application on the thickness of the skin fold of guinea pigs and rabbits (in $\mathrm{mm}$ )

\begin{tabular}{|c|c|c|}
\hline \multirow{2}{*}{ Groups of animals } & \multicolumn{2}{|c|}{ Skin fold thickness, mm } \\
\cline { 2 - 3 } & Guinea pigs & Rabbits \\
\hline Group 1 (negative control) & $2.31 \pm 0.04$ & $3.17 \pm 0.09$ \\
\hline Group 2 (2 mg/kg) & $2.34 \pm 0.05$ & $3.11 \pm 0.07$ \\
\hline Group 3 (5 mg/kg) & $2.30 \pm 0.03$ & $3.14 \pm 0.07$ \\
\hline Group 4 (20 mg/kg) & $2.37 \pm 0.04$ & $3.18 \pm 0.08$ \\
\hline
\end{tabular}

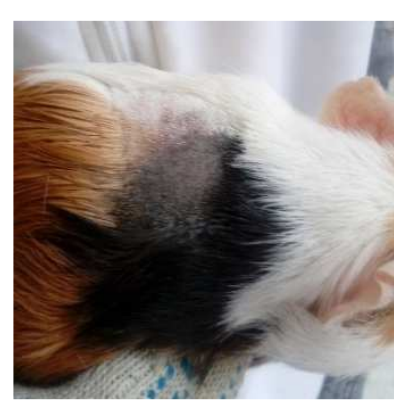

1

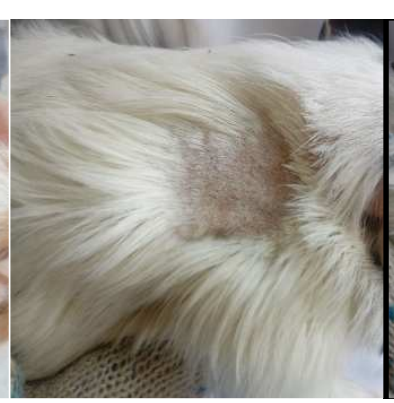

2

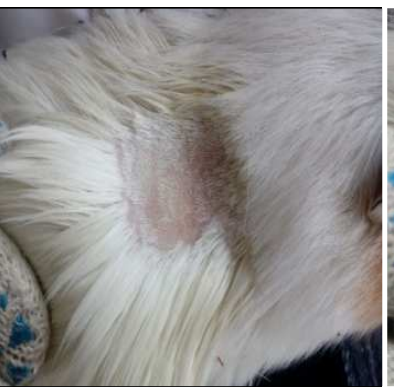

3

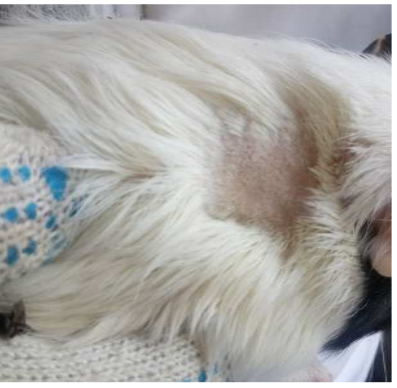

4

Fig. 1. Assessment of bisphenol-5 sensitizing (irritant) effect on guinea pigs' skin. 1is liquid paraffin (control); 2, 3 and 4 are specimens of $2 \mathrm{mg} / \mathrm{kg}, 5 \mathrm{mg} / \mathrm{kg}$ and $20 \mathrm{mg} / \mathrm{kg}$, respectively (experience)

The study of the bisphenol-5 sensitizing effect after 10 and 20 repeated skin applications showed that no visible changes in the form of hyperemia, infiltration or peeling were observed, which indicates the absence of body sensitization. The skin reaction in the experimental groups of animals did not differ from that of the control ones. The results obtained on the scale of assessing skin samples correspond to 0 points (table. 2).

The skin fold thickness in the clipped and shaved areas in guinea pigs and rabbits of the experimental groups did not significantly differ from the control animals during the two-week observation period as well. The results of the effect of the studied antioxidant with multiple applications on the thickness of guinea pigs' and rabbits' skin folds are presented in table 4 .

Table 4. Effect of bisphenol-5 with multiple applications on the thickness of the guinea pigs' and rabbits' skin folds (in $\mathrm{mm}$ )

\begin{tabular}{|c|c|c|}
\hline \multirow{2}{*}{ Groups of animals } & \multicolumn{2}{|c|}{ Skin fold thickness, mm } \\
\cline { 2 - 3 } & Guinea pigs & Rabbits \\
\hline Group 1 (negative control) & $2,45 \pm 0,06$ & $3,36 \pm 0,08$ \\
\hline Group 2 (2 mg/kg) & $2,41 \pm 0,08$ & $3,38 \pm 0,06$ \\
\hline Group 3 $(5 \mathrm{mg} / \mathrm{kg})$ & $2,48 \pm 0,07$ & $3,32 \pm 0,09$ \\
\hline Group 4 $(20 \mathrm{mg} / \mathrm{kg})$ & $2,43 \pm 0,05$ & $3,38 \pm 0,08$ \\
\hline
\end{tabular}

After dermal administration of bisphenol-5 with guinea pigs and rabbits, the general condition of the animals was satisfactory, the weight of the animals corresponded to the age-related physiological norm, and no changes in the behavior and appetite of the animals were detected.

No significant differences were also found in body temperature and live weight in the control and experimental groups of animals. The areas of skin after cutting and shaving were equally quickly overgrown with young hair, which did not differ in density in the experimental and control groups of animals. Thus, the skin condition of rabbits treated with the studied antioxidant at the doses of $2,5,20 \mathrm{mg} / \mathrm{kg}$ did not change (no reaction).

There were no signs of hyperemia and other changes in the condition of the skin. The thickness of the skin fold at the site of substance application did not increase in comparison to the initial state. Consequently, bisphenol-5 does not have an allergenic effect on tissues in the area of its application, which makes it possible to classify the substance as a class 1 substance in terms of skin irritating properties. 
In the second series of experiments, the sensitizing (irritant) effect of bisphenol-5 was determined by conjunctival tests. For the sample, alcohol solutions of the drug were prepared at the doses of 2,5 and 20 $\mathrm{mg} / \mathrm{kg}$.

The study was carried out on guinea pigs and rabbits, which were administered with one drop of the test drug on a conjunctiva under upper eyelids of right eyes. The control animals were injected with $2 \%$ alcohol in the second eye.

The clinical condition of the animals, as well as changes in the blood supply to the conjunctiva, the presence of secretions, the condition of the cornea and eyelids, were established after 15 (immediate hypersensitivity) and 30 minutes, 1, 2, 4, 8, 24 and 48 (delayed reaction) hours after the drug application.

A study of the effect of bisphenol-5 on the conjunctiva of the guinea pigs' eyes showed that the test agent did not cause irritation of the conjunctiva, both immediately after instillation and throughout the study. 15 minutes after instillation of the drug in the eye, conjunctival redness (hyperemia), lacrimation, corneal opacity were not observed; iris did not have any visible changes, chymotosis (conjunctival edema) was absent. After 24-48 hours, corneal opacities were also not observed, the iris did not have any visible changes, conjunctival edema was absent.

The application of the antioxidant to experimental and control animals did not reveal the difference in conjunctival reaction, both immediate and delayed. The test results confirm the absence of conjunctival reaction in rabbits after 15 minutes and 24-48 hours to instill the studied drug. After the visual assessment of the condition of the conjunctiva, cornea and eyelids of the animals' eyes, it was found that there were no differences between the control and experimental groups.

Throughout the study, there was no hypermia, swelling of the eyelids and discharge from the eyes, redness and swelling of the lacrimal duct, conjunctiva and sclera; the cases of the cornea clouding were also not detected. During the experiment, the normal state of the vessels of the eyelids (not dilated), bulbar conjunctiva and cornea of the eyes of experimental animals was noted. As a result of clinical studies of the state of the guinea pigs' and rabbits' bodies after application of bisphenol-5, no changes in body temperature, pulse rate and number of respiratory movements were observed.

The general condition of the animals was satisfactory, the behavior corresponded to this type of animal, intensive motor movements, they actively moved in the cage, there were no cramps, the movements of animals were coordinated, the reaction to sound, tactile and pain, sound stimuli was preserved. The coat was smooth, shiny, the hair was firmly held in the hair follicles. The mucous membranes were pale pink in color without hemorrhages and ulcerations.

Thus, during the production of conjunctival samples, the experimental and control animals showed the absence of hypersensitivity, both immediate and delayed type, with respect to bisphenol-5. Consequently, the test drug is not toxic when staging conjunctival samples in laboratory animals.

\section{Conclusion}

The studies of the allergenic effect on guinea pigs and rabbits showed that the antioxidant bisphenol-5 does not have a negative effect on the body of laboratory animals and, in terms of the severity of allergenic properties, it can be classified as hazard class 4 substances, as lowhazard substances.

\section{References}

1. K.M. Tireuov, G.M. Rakhimzhanova, Probl. of the agricult. market 2, 131-137 (2019)

2. E.V. Skvortsov, R.S. Muhammadiev, R.S. Muhammadiev et al., Sci. notes of Kazan State Acad. of Veter. Med. named after N.E. Bauman 1(241), 187-192 (2020)

3. K.A. Afanasyev, Bull. of Altai State Agrar. Univer. 4(150), 110-116 (2017)

4. O.A. Krasnova, Relevant probl. of the intens. development of animal husbandry 19(1), 72-77 (2016)

5. S.D. Batanov, O.A. Krasnova, E.V. Khardina, A.Yu. Borisov, Niva Volga 1(26), 71-75 (2013)

6. O.A. Krasnova, E.V. Khardina, M.V. Loshkareva, Bull. of ASAU 4(162), 111-115 (2018)

7. P.S. Ostapchuk, D.V. Zubochenko, T.A. Kuevda, Agricult. Sci. of the Euro-North-East 20(2), 103117 (2019)

8. A.J. Yeates, E.M. McSorley, G.J. Cuskelly et al., Meat Sci. 84(1), 1-13 (2010)

9. K.W. McMillin, Reciprocal Meat Conf. Proc., 49, 53-64 (1996)

10. N.R. Kasanova, Sci. notes of the Kazan State Acad. of Veter. Med. named after N.E. Bauman 202, 101105 (2010)

11. G.I. Boryaev, E.V. Zdorovieva, Yu.N. Fedorov, Yu.V. Kravchenko, Niva of the Volga reg. 3, 49-55 (2012)

12. R. Akhmadullin, D. Gatiyatullin, N. Mukmeneva et al., Biolog. Chem. Sci. 5(6), 494-502 (2014)

13. M. Şentürk, İ. Gülçin, A. Daştan et al., Bioorganic and Med. Chem. 17(8), 3207-3211 (2009)

14. A.N. Mironov, Guidelines for preclinical studies of drugs (Grif and K, Moscow, 2012)

15. M.V Arisov, I.P. Belykh, V.V. Artemov, Veterinar. 4, 32-35 (2018)

16. V.P. Fisenko, Guide to the experimental (preclinical) study of new pharmacological substances (Remedium, Moscow, 2000)

17. B.I. Lyubimov, L.P. Kovalenko, V.N. Fedoseyeva, A.S. Ivanova, Guidelines for evaluat. the allerg. properties of pharmacolog. agents $\mathbf{9 8 ( 3 0 0 ) , 4 - 1 2}$ (1998) 
18. W.O. Weigle, C.G. Cochrane, F.J. Dixon, J. Immunol. 85, 469-477 (1960)
19. R.U. Khabrieva, Manual on the experimental (preclinical) study of new pharmacological substances (Medicine, Moscow, 2005) 